\title{
Pharmacy's Call for Authorities to Aggressively Enforce Laws Addressing Price Gouging
}

\author{
T. Joseph Mattingly II, PharmD, MBA, PhD, and Michael D. Hogue, PharmD, FAPhA, FNAP
}

\begin{abstract}
SUMMARY
Early reports of potential treatment for coronavirus disease (COVID-19) have raised concerns related to pharmaceutical distribution. Despite the lack of high-quality evidence, the mere hope of effectiveness of potential treatments, such as hydroxychloroquine, has led to surges in demand for these products, and many pharmacists are already informally reporting shortages through social channels. As manufacturers and wholesale distributors struggle to fulfill orders for drugs such as hydroxychloroquine, short-term price increases may seem reasonable in a free market when demand increases. However, any price increases by manufacturers, wholesale distributors, and pharmacies might be seen as exploitive gouging of consumers during a declared emergency. In addition to concerns of price gouging, increases in prescription drug utilization during the pandemic may lead to increases in spending for all payers as members may be treated for COVID-19. This article explores pharmaceutical supply chain and drug pricing nuances that may cause problems for payers and pharmacies as the country battles this global pandemic.
\end{abstract}

J Manag Care Spec Pharm. 2020;26(8):952-55

Copyright @2020, Academy of Managed Care Pharmacy. All rights reserved.

$\mathrm{R}$ ecent events have created considerable uncertainty regarding pharmaceuticals and related health services in response to coronavirus disease (COVID-19) and the rapid spread of cases around the world. ${ }^{1,2}$ While there are currently no pharmaceutical treatments approved by the U.S. Food and Drug Administration for COVID-19, case reports, open-label studies, and off-label uses of products such as chloroquine, hydroxychloroquine, azithromycin, and lopinavirritonavir have been mentioned in the media, by the president of the United States, and by the Centers for Disease Control and Prevention. ${ }^{3}$ Despite the lack of high-quality clinical evidence, the mere hope of effectiveness has led to dramatic increases in demand for these products, and many pharmacists are already reporting shortages through social channels. Public health experts have previously described "gaming" during a declared emergency as intentional efforts to acquire and allocate essential resources without medical justification. ${ }^{4}$ From individuals stealing defibrillators in the aftermath of Hurricane Katrina to mass hysteria related to anthrax exposure after September 11, 2001, causing "black market" distribution of ciprofloxacin, gaming and price gouging in the wake of a declared emergency can harm consumers physically through inadequate supplies, as well as economically as a result of inappropriate price increases. ${ }^{4}$
As the world struggles to respond to the current public health crisis, the American Pharmacists Association recently convened its first virtual House of Delegates to approve specific policy statements to address growing concerns for its members (Figure 1).

This commentary provides context around the potential issue of drug price increases over the upcoming months as it relates to COVID-19.

Price of Potential COVID-19 Drugs at Different Links in the Supply Chain

U.S. pharmaceutical prices for chloroquine, hydroxychloroquine, and lopinavir-ritonavir vary greatly depending on the drug price definition used (Table 1). The list price, or wholesale acquisition cost, refers to the purchase price at the wholesale distribution level before rebates or discounts are applied. ${ }^{5}$ The average wholesale price (AWP) represents the price that a wholesaler may charge a pharmacy before rebates or discounts, while the National Average Drug Acquisition Costs (NADAC) surveys pharmacies to estimate a more accurate pharmacylevel drug price. ${ }^{5,6}$ The Department of Veterans Affairs Federal Supply Schedule price point accounts for some of the largest discounts off list price and is likely the lower bound estimates of the net price for each drug. ${ }^{7}$ The retail price available on GoodRx.com may provide the best available estimate for a cash-paying patient price. ${ }^{5,8}$ Because of the complexity of drug pricing and reimbursement in the United States, none of these prices reflect the actual net price paid by the insurer, pharmacy, or out-of-pocket patient cost, all of which have considerable variability based on contracts and benefit design.

\section{Short-Term Price Spikes and Dispensing} Pharmacy Challenges

As manufacturers and wholesale distributors work to fulfill orders for drugs such as hydroxychloroquine, short-term price increases may seem reasonable in a free market when demand increases. Any price increases by manufacturers, wholesale distributors, and pharmacies might be seen as gouging consumers during a national emergency. However, more than $90 \%$ of the U.S. population are insured patients who are protected from the full exposure of the price increase by their health plans' pharmacy benefits managers (PBMs), which have set contract prices with pharmacies and further rebates and discounts from manufacturers. ${ }^{9}$ A price increase at the manufacturer or 
FIGURE 1 Policy Passed March 20, 2020, by the APhA Regarding Pricing and Quality During Times of Emergency

Pharmaceutical Safety and Access During Emergencies

1. APhA urges government authorities to hold pharmaceutical manufactures, wholesalers, pharmacies and other pharmaceutical supply distributors, and providers accountable to state and federal price gouging laws in selling those items to patients, pharmacies, hospitals, and other health care providers during times of local, state, or national emergency.

2. APhA urges government authorities to aggressively enforce laws and regulations against adulterated products and false and misleading claims by entities offering to sell pharmaceutical and medical products to health care providers and consumers.

APhA = American Pharmacists Association.

wholesale distribution level would ultimately stop at the dispensing pharmacy, which would potentially bear the losses as the acquisition costs for the drugs eclipse the maximum reimbursement allowed. This is particularly troubling, since community pharmacies have stepped up as essential responders to the crisis, putting pharmacy staff at considerable risk.

For example, the Affordable Care Act revised the federal upper limit (FUL) calculation based on the most recently reported monthly average manufacturer price (AMP) reported and certified by manufacturers. ${ }^{10}$ This FUL may be used by health plans to set maximum allowable cost (MAC) limits on generic drugs such as hydroxychloroquine. Over the 12 months before the U.S. surge in COVID-19 cases (February 2019-February 2020), the AMP and FUL were actually declining (Figure 2). If these prices increased in March 2020, the potential lag in reporting and analysis, combined with contracting often done on an annual basis, may put many dispensing pharmacies in a scenario forced to dispense at a loss.

Exploring the hypothetical example of a pharmacy dispensing a short course (12 tablets) of hydroxychloroquine to an insured patient from a typical community pharmacy can be quite informative. In Table 2, we modeled 2 different hypothetical contracting scenarios: (1) reimbursement using a typical brand drug formula to estimate revenue at "AWP - 15\% + \$0.50 dispensing fee" and (2) a typical generic drug formula to estimate revenue at "AWP $-80 \%+\$ 0.50$ dispensing fee." Assuming that the pharmacy's acquisition costs are at the national average (NADAC), we see that dispensing a generic prescription such as hydroxychloroquine may already deliver small margins and that short-term increases in acquisition costs could quickly put the pharmacy in a significant financial loss. After accounting for operating costs to dispense the prescription at $\$ 14.00$ per prescription (using 2019 operating costs of the pharmacy segments reported by CVS and Walgreens), the pharmacy margins quickly disappear, and any further price increases at the wholesale level would only amplify losses (Table 2).

These hypothetical scenarios do not account for other contractual obligations typically observed in pharmacy contracts, such as direct and indirect remuneration (DIR). Pharmacies that dispense medications to Medicare beneficiaries under Medicare Part D may be subject to retroactive DIR fees designed to drive performance metrics of the pharmacy network. ${ }^{11}$ For example, the Medicare Part D prescription drug plan may stipulate that DIR fees are contingent upon medication

TABLE 1 Current Price-per-Unit for Existing Medications that Are Currently Not Approved for COVID-19 But Recognized by the CDC as Potential Treatments ${ }^{3,5,6}$

\begin{tabular}{|c|c|c|c|c|c|c|c|}
\hline Generic Name & Available & WAC, $\$$ & AWP, \$ & NADAC, $\$$ & VAFSS, $\$$ & GoodRx, \$ & MAC, \$ \\
\hline \multirow[t]{2}{*}{ Chloroquine } & $250 \mathrm{mg}$ tablets & 1.28 & 2.46 & $\mathrm{NA}$ & $\mathrm{NA}$ & 2.03 & $\mathrm{NA}$ \\
\hline & $500 \mathrm{mg}$ tablets & 3.36 & 5.42 & 9.84 & NA & 2.48 & $\mathrm{NA}$ \\
\hline Hydroxychloroquine & $200 \mathrm{mg}$ tablets & 0.52 & 1.83 & 0.29 & 0.10 & 0.34 & $\mathrm{NA}$ \\
\hline \multirow[t]{3}{*}{ Lopinavir-ritonavir } & $\begin{array}{l}80 \mathrm{mg}-20 \mathrm{mg} / \mathrm{lmL} \text { oral } \\
\text { solution }^{2}(160 \mathrm{~mL} \text { bottle })\end{array}$ & 386.83 & 522.18 & NA & 355.98 & 163.22 & NA \\
\hline & $100 \mathrm{mg}-25 \mathrm{mg}$ tablets & 4.27 & 5.12 & NA & 3.12 & 4.28 & NA \\
\hline & $200 \mathrm{mg}-50 \mathrm{mg}$ tablets & 8.53 & 10.24 & 8.29 & 6.12 & 8.48 & NA \\
\hline
\end{tabular}

a Unit for oral solution is 1 whole bottle $(160 \mathrm{~mL})$

AWP = average wholesale price; $C D C=$ Centers for Disease Control and Prevention; $M A C=$ maximum allowable cost; NA =not applicable; NADAC = National Average Drug Acquisition Costs; VAFSS = Veterans Affairs Federal Supply Schedule; WAC = wholesale acquisition cost. 


\section{FIGURE 2 Affordable Care Act FUL Based on the Weighted Average of the Most Recently Reported Monthly} AMP for a Single Hydroxychloroquine $200 \mathrm{mg}$ Tablet on a Nationwide Basis ${ }^{10}$

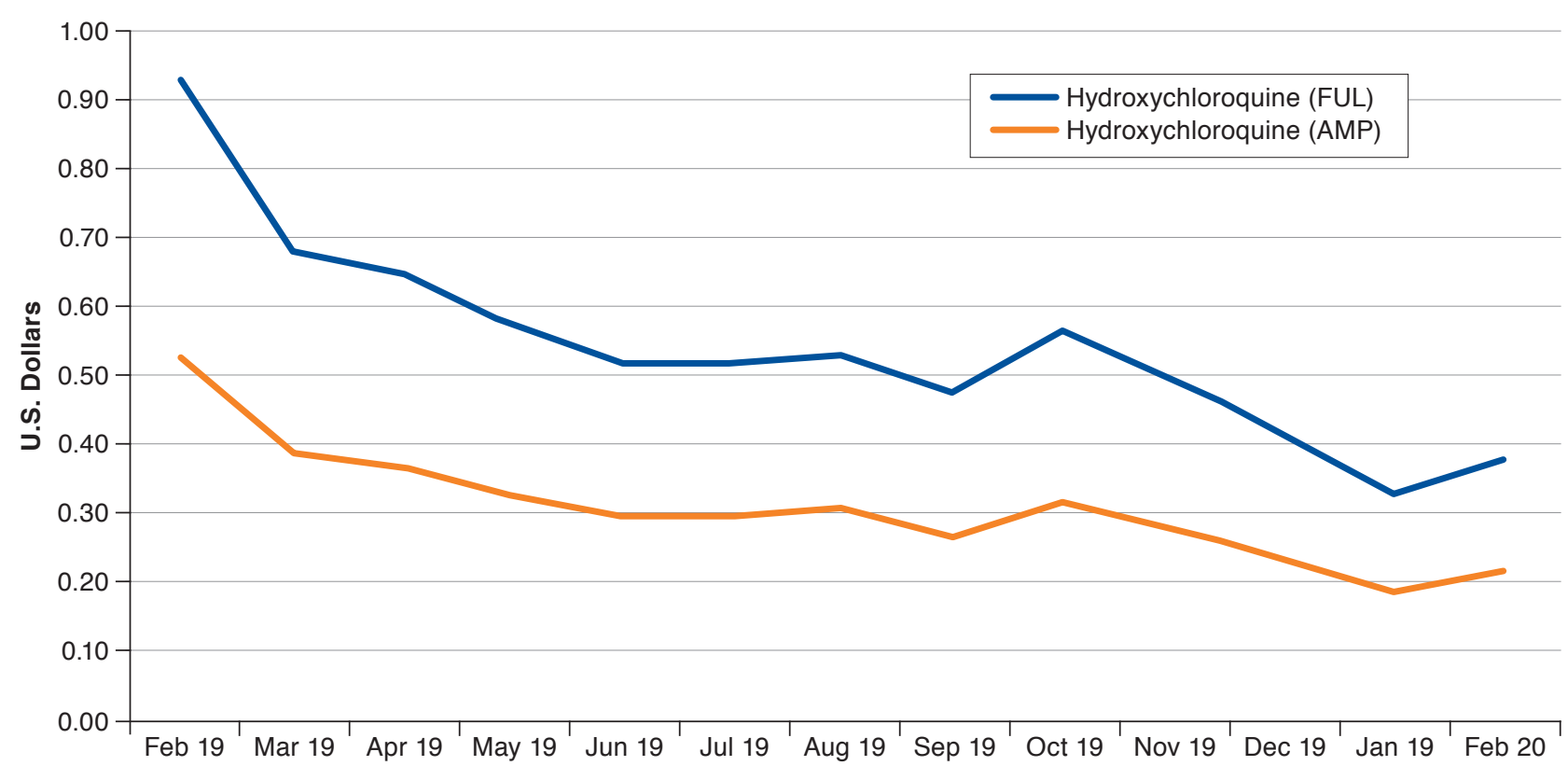

$A M P=$ average manufacturer price; $F U L=$ federal upper limit.

adherence, medication therapy management consultations, reducing high-risk medication use, or customer satisfaction metrics. ${ }^{12}$ Any DIR fees applied to medications related to COVID-19 and potentially all dispenses during a state of national emergency are inappropriate, since the pharmacy networks will be operating at a less than ideal state to meet standard performance expectations.

\section{Short-Term Price Spikes and Payer Challenges}

Broad increases in health care utilization during the pandemic may lead to increases in spending for all payers, since plan members (who would typically not be needing to use the medical or pharmacy benefit) may contract COVID-19 or require testing to rule out COVID-19. Some insurers have taken additional steps to waive copayments on any COVID-19 testing or treatment. ${ }^{13}$ Other concerns may relate to existing contracts, particularly for PBMs who do not have contractual price protections with the manufacturers of generic products and may be at risk for increases in their acquisition costs. For payers without price protection language in the contracts with pharmacies in the pharmacy network, any short-term spikes could be problematic. The major PBMs also own outpatient pharmacies and large mail order operations. While many PBMowned mail order pharmacies may not dispense antibiotics or antimalarials (such as hydroxychloroquine), price increases for lopinavir-ritonovir could certainly apply to their operations.

\section{Conclusions}

Pharmacies, as the terminal point in the pharmaceutical supply chain, may be at risk of suffering price gouging by manufacturers, wholesalers, or mid-market opportunists. Price gouging laws, largely designed and intended to protect consumers, could reasonably be applied to pharmacies in the event that PBMs and other payers are unable to adjust or update their reimbursed prices based on the wide fluctuations that can be seen in market prices. In fact, current pharmacy reimbursement from PBMs that may be based on MAC pricing may not reflect actual market pricing of generic products in short supply, leaving pharmacies "holding the bag" with significant net losses.

It seems as though pharmacies are caught in the middle without reasonable protections against sudden and significant price increases for products that may already be reimbursed at amounts near their acquisition costs while, at the same time, serving an essential public health role during this national crisis. Also, PBMs without adequate price protections may be exposed to larger acquisition costs in their pharmacy networks. In terms of the pharmaceutical supply chain, pharmacies as the last purchaser before patient dispensing need to be protected as "consumers" by federal, state, and local government price gouging laws. Pharmacies should also be assured of reasonable reimbursement to protect the very thin margins that we have described. Accordingly, every entity across the supply chain should be afforded this protection, including PBMs, if they are 
TABLE 2 Modeled Impact of Potential Hydroxychloroquine Drug Price Gouging on Dispensing Pharmacies

\begin{tabular}{|c|c|c|c|}
\hline Operating Statement & $\begin{array}{l}\text { Hydroxychloroquine } 200 \mathrm{mg} \\
\text { Tablets at Current Prices, } \$\end{array}$ & $\begin{array}{l}\text { Hydroxychloroquine at } \\
2 \times \text { Price, } \$\end{array}$ & $\begin{array}{c}\text { Hydroxychloroquine at } \\
10 \times \text { Price, } \$\end{array}$ \\
\hline \multicolumn{4}{|c|}{ Revenue at AWP $-15 \%+\$ 0.50$} \\
\hline Revenue & 19.17 & 19.17 & 19.17 \\
\hline Cost of goods sold & 3.48 & 6.96 & 34.80 \\
\hline Margin & 15.69 & 12.21 & $(15.63)$ \\
\hline Operating expense & 14.00 & 14.00 & 14.00 \\
\hline Net income before taxes & 1.69 & $(1.79)$ & $(29.63)$ \\
\hline \multicolumn{4}{|c|}{ Revenue at AWP $-80 \%+\$ 0.50$} \\
\hline Revenue & 4.89 & 4.89 & 4.89 \\
\hline Cost of goods sold & 3.48 & 6.96 & 34.80 \\
\hline Margin & 1.41 & $(2.07)$ & $(29.91)$ \\
\hline Operating expense & 14.00 & 14.00 & 14.00 \\
\hline Net income before taxes & $(12.59)$ & (11.93) & $(43.91)$ \\
\hline
\end{tabular}

Note: Red figures indicate a financial loss.

a2020 U.S. dollars.

AWP $=$ average wholesale price.

subjected to clear price gouging or gaming of essential products during a national emergency. By doing so, during times of declared emergencies, manufacturers and suppliers of pharmaceuticals would be prohibited from escalating prices past the point of normal inflation.

\section{Authors}

T. JOSEPH MATTINGLY II, PharmD, MBA, PhD, Department of Pharmaceutical Health Services Research, University of Maryland School of Pharmacy, Baltimore, and MICHAEL D. HOGUE, PharmD, FAPhA, FNAP, Loma Linda University School of Pharmacy and Center for Interprofessional Education, Loma Linda, California.

AUTHOR CORRESPONDENCE: T. Joseph Mattingly II, University of Maryland School of Pharmacy, 220 Arch St., 12th Fl., Baltimore, MD 21201. Tel.: 410.706.8068; Email: jmattingly@rx.umaryland.edu.

\section{DISCLOSURES}

No funding supported the writing of this article. Mattingly reports unrelated consulting fees from the National Health Council, Bristol Myers Squibb, G\&W Laboratories, Allergy and Asthma Foundation of American, and the Massachusetts Health Policy Commission. Hogue has nothing to disclose.

\section{REFERENCES}

1. Fauci AS, Lane HC, Redfield RR. Covid-19—navigating the uncharted. N Engl J Med. 2020;382(13):1268-69.

2. Tatelbaum J. Fears of US drug shortages grow as India locks down to curb the coronavirus. CNBC. March 24, 2020. Available at: https://www.cnbc. com/2020/03/24/us-drug-shortage-fears-grow-as-india-locks-down-due-tothe-coronavirus.html. Accessed April 15, 2020.

3. Centers for Disease Control and Prevention. Information for clinicians on therapeutic options for COVID-19 patients. Updated April 13, 2020. Available at: https://www.cdc.gov/coronavirus/2019-ncov/hcp/therapeuticoptions.html\#r7. Accessed April 15, 2020.
4. Hodge JG, White LC, Sniegowski A. Public health and the law: gaming the system during public health emergencies. J Law Med Ethics. 2012;40(3):690-95.

5. IBM Watson Health. IBM Micromedex REDBOOK Online [online database]. February 2019. Available at: https://www.ibm.com/products/micromedex-red-book. Accessed April 15, 2020.

6. Centers for Medicare \& Medicaid Services. NADAC (National Average Drug Acquisition Cost). 2020. Available at: https://data.medicaid.gov/DrugPricing-and-Payment/NADAC-National-Average-Drug-Acquisition-Cost-/ a4y5-998d/data. Accessed April 15, 2020

7. Levy J, Rosenberg M, Vanness D. A transparent and consistent approach to assess US outpatient drug costs for use in cost-effectiveness analyses. Value Health. 2018;21(6):677-84.

8. Luo J, Kulldorff M, Sarpatwari A, Pawar A, Kesselheim AS. Variation in prescription drug prices by retail pharmacy type a national cross-sectional study. Ann Intern Med. 2019;171(9):605-11.

9. Berchick ER, Barnett JC, Upton RD. Health insurance coverage in the United States: 2018. U.S. Census Bureau. November 8, 2019. Available at: https://www.census.gov/library/publications/2019/demo/p60-267.html. Accessed April 15, 2020.

10. Centers for Medicare \& Medicaid Services. Federal upper limits. Updated May 7, 2019. Available at: https://www.medicaid.gov/medicaid/prescription-drugs/federal-upper-limits/index.html. Accessed April 15, 2020.

11. Anderson GF, Bai G. Reforming direct and indirect remuneration in Medicare Part D. Health Affairs Blog. February 19, 2019. Available at: https://www.healthaffairs.org/do/10.1377/hblog20190215.708286/full/. Accessed April 15, 2020.

12. Liner DM, Margiott TA. Value of direct and indirect remuneration (DIR): impact on Medicare Part D prescription drug plan (PDP) program stakeholders. Pharmaceutical Care Management Association. July 2017. Available at: https://www.pcmanet.org/wp-content/uploads/2017/07/Value-of-PDPDIR_20170706.pdf. Accessed April 15, 2020.

13. America's Health Insurance Plans. Health insurance providers respond to coronavirus (COVID-19). Blog. 2020. Available at: https://www.ahip.org/ health-insurance-providers-respond-to-coronavirus-covid-19/. Accessed April 15, 2020. 